\title{
Klasifikasi Objek Kode Tangan pada Pengenalan Isyarat Alphabet Bahasa Isyarat Indonesia (Bisindo)
}

\author{
Rohmat Indra Borman*, Bentar Priopradono, Abdul Rahman Syah \\ Jurusan Informatika, Fakultas FTIK \\ Universitas Teknokrat Indonesia \\ Jl. Abidin Pagar Alam No.9 -11, Bandar Lampung \\ rohmat_indra@teknokrat.ac.id*,abdul_rahman@gmail.com
}

\begin{abstract}
Abstrak - Alat komunikasi penyandang tunarungu adalah dengan bahasa isyarat. yang digunakan oleh penyandang tunarungu adalah Bahasa Isyarat Indonesia (Bisindo) yang digalakan Gerakan Kesejahteraan Tunarungu Indonesia (Gerkatin). Untuk berkomunikasi dengan orang normal yang tidak mengetahui bahasa isyarat biasanya membutuhkan seorang perantara yang menerjemahkan bahasa isyarat. Untuk mempermudah dalam berkomunikasi dan mengenal bahasa isyarat khususnya Bahasa Isyarat Indonesia (Bisindo) diperlukan deteksi terhadap kode tangan dalam bahasa isyarat dan mengklasifikasikannya sehingga dapat di konversi menjadi sebuah text yang dapat dipahami orang pada umumnya. Dalam mengenali objek kode tangan pada bahasa isyarat proses penting yang harus diperhatikan adala dengan mendeteksi konfigurasi bentuk tangan yang mencerminkan huruf alphabet pada Bisindo. Metode deteksi objek tangan yang digunakan menggunakan Haar Classifier. Setelah kode tangan telah terdeteksi maka langkah selanjutnya adalah proses pengambilan citra, pelatihan data, dan klasifikasi tangan dapat dilakukan. Untuk itu proses klasifikasi objek kode tangan merupakan proses yang penting dalam pengenalan bahasa isyarat untuk dapat ditransformasikan kedalam bentuk huruf pada umumnya K-Nearest Neighbor (K-NN) merupakan sebuah metode yang digunakan untuk melakukan klasifikasi terhadap objek berdasarkan data pembelajaran yang jaraknya paling dekat dengan objek tersebut. Dari hasil pengujian klasifikasi objek kode tangan pada bahasa isyarat dengan algoritma $K$ Nearest Neighbor huruf alphabet yang dapat diterjemahkan yaitu huruf A, B, C, D, E, F, G, H, I, K, L, M, N, O, P, Q, S, T, U, $\mathrm{V}, \mathrm{W}, \mathbf{X}, \mathbf{Y}$, dan $\mathrm{Z}$. Huruf $\mathbf{J}$ dan $\mathbf{R}$ tidak dapat diterjemahkan karena berbentuk gerakan tangan. Dari hasil pengujian ratarata hasil akhir yang di dapat $91,8 \%$.
\end{abstract}

Kata kunci : bahasa isyarat; Bisindo; Haar Classifier; K-NN.

\section{PENDAHULUAN}

Penyandang tunarungu dalam berkomunikasi dengan sesama penyandang tunarungu atau kepada masyarakat normal dengan menggunakan bahasa isyarat. Bahasa isyaratnya biasanya dalam bentuk gerakan tangan, mimik, tubuh yang membentuk simbol-simbol yang mengartikan suatu huruf atau kata. Metode bahasa isyarat yang digunakan oleh penyandang tunarungu salah satunya adalah Bahasa Isyarat Indonesia
(Bisindo). Bisindo merupakan bahasa yang digalakkan Gerakan Kesejahteraan Tunarungu Indonesia (Gerkatin) dan dikembangkan oleh masyarakat tunarungu sendiri, sehingga Bisindo menjadi sistem komunikasi yang praktis dan efektif untuk penyandang tunarungu di Indonesia karena Bisindo lahir dari penyandang tunarungu itu sendiri[1]. Bahasa isyarat berupa kode-kode gerakan tangan. Untuk menerjemahkan citra kode gerakan tangan dibutuhkan pengolahan citra digital. Citra merupakan input untuk pengolahan citra sedangkan outputnya adalah hasil dari pengolahan citra[2]. Dalam mengenali objek kode tangan pada bahasa isyarat proses penting yang harus diperhatikan adalah dengan mendeteksi konfigurasi bentuk tangan yang mencerminkan huruf alphabet pada Bisindo. Metode deteksi objek tangan yang digunakan menggunakan Haar Classifier.

Setelah kode tangan telah terdeteksi maka langkah selanjutnya adalah proses pengambilan citra, pelatihan data dan klasifikasi tangan dapat dilakukan. Untuk itu proses klasifikasi objek kode tangan merupakan proses yang penting dalam pengenalan bahasa isyarat untuk dapat ditransformasikan kedalam bentuk text. Algoritma K-NN merupakan algoritma yang menentukan nilai jarak pada pengujian data testing dengan data training berdasarkan nilai terkecil dari nilai ketetanggaan terdekat[3].

Pada beberapa penelitian K-NN dinilai mampu melakukan klasifikasi dengan baik. Pada penelitian klasifikasi daging sapi dan daging babi dengan K-Nearest Neighbor (K-NN) menghasilkan tingkat akurasi $93,33 \%$ untuk pengujian tanpa background[4]. Pada penelitian lain klasifikasi daun dengan perbaikan fitur citra menggunakan metode K-Nearest Neighbor (K-NN) dengan menghasilkan tingkat akurasi 86,67\%[5]. Selain itu pada penelitian yang membandingkan metode K-Nearest Neighbor (K-NN) dan metode Nearest Cluster Classifier (NCC) dalam pengklasifikasian kualitas batik tulis dengan hasil rata-rata keberhasilan $\mathrm{K}-\mathrm{NN}$ dalam klasifikasi adalah $99.11 \%$, sedangkan metode NCC rata-rata keberhasilan dalam klasifikasi sebesar $86.44 \%[6]$.

Pada penelitian ini akan dilakukan klasifikasi objek kode tangan dengan metode K-Nearest Neighbor (K-NN) pada Bahasa Isyarat Indonesia (Bisindo) dalam menterjemhakan bahasa isyarat berupa 26 huruf alphabet dalam bentuk capture image dengan alat bantu kamera web cam kedalam bentuk huruf pada umumnya. 


\section{METODE}

\section{A. Pengumpulan Data}

Data yang digunakan untuk masukan pada pada penlitian ini berupa gambar bahasa isyarat tangan Bisindo yang sebelum dilakukan training sample terlebih dahulu untuk mendapatkan gambar yang sesuai dengan huruf alphabet bahasa isyarat Bisindo, kemudian masing-masing huruf akan diambil 50 gambar lalu disimpan dalam folder sesuai dengan nama huruf alphabet. Contoh gambar hasil training sample. Data kode gerakan tangan disesuaikan dengan kode tangan alphabet yang diambil dari buku Bahasa Isyarat Indonesia (Bisindo) yang diterbitkan oleh DPD Gerakan Kesejahteraan Tunarungu Indonesia (Gerkatin) DKI Jakarta dapat dilihat pada Gambar 1 .

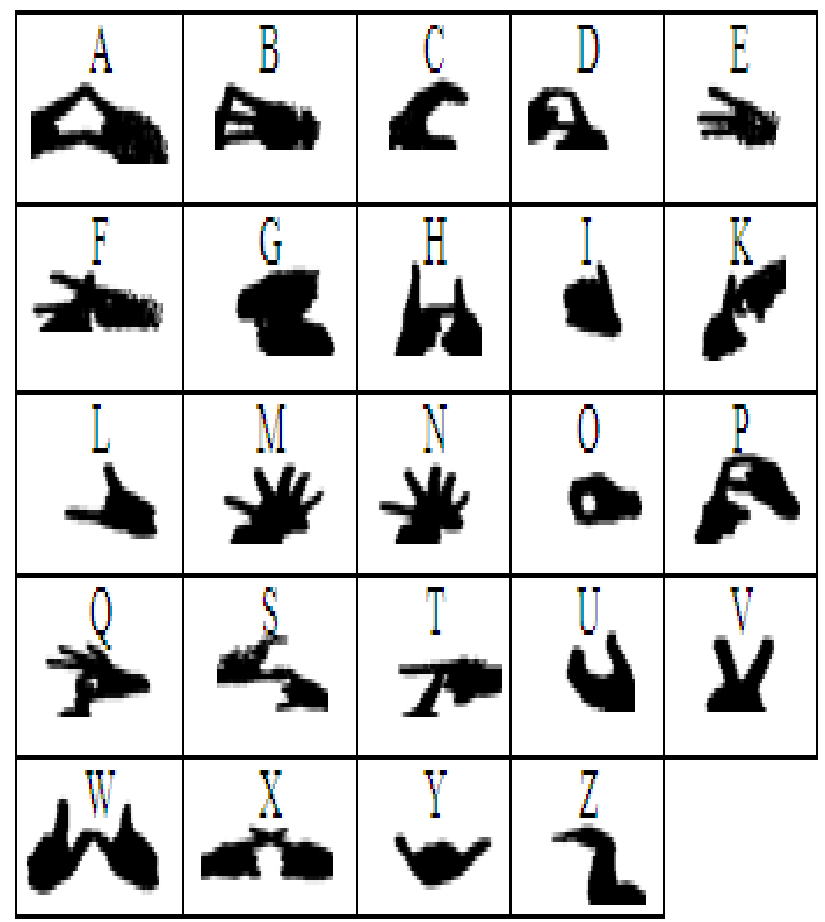

Gambar 1. Data training sample Bahasa Isyarat Indonesia (BISINDO)

\section{B. Rancangan dan Pemodelan}

Untuk mengklasifikasikan kode objek tangan pada bahasa isyarat dibutuhkan rancangan dan pemodelan untuk mengimplementasikan penerjemah bahasa isyarat yang akan dibuat. Maka dibutuhkan ilustrasi dari system yang akan dikembangkan melalui blok diagram. Ilustrasi sistem ini mengilustrasikan mengenai konsep sistem yang akan dibangun. Sistem yang akan dibuat menggunakan webcam untuk menangkap objek, bahasa isyarat tangan sebagai objek dengan pola yang telah ditentukan dimana akan diidentifikasi sehingga akan menampilkan arti bahasa isyarat yang telah dimasukan (input) sebelumnya. Ilustrasi system dapat dilihat pada Gambar 2.

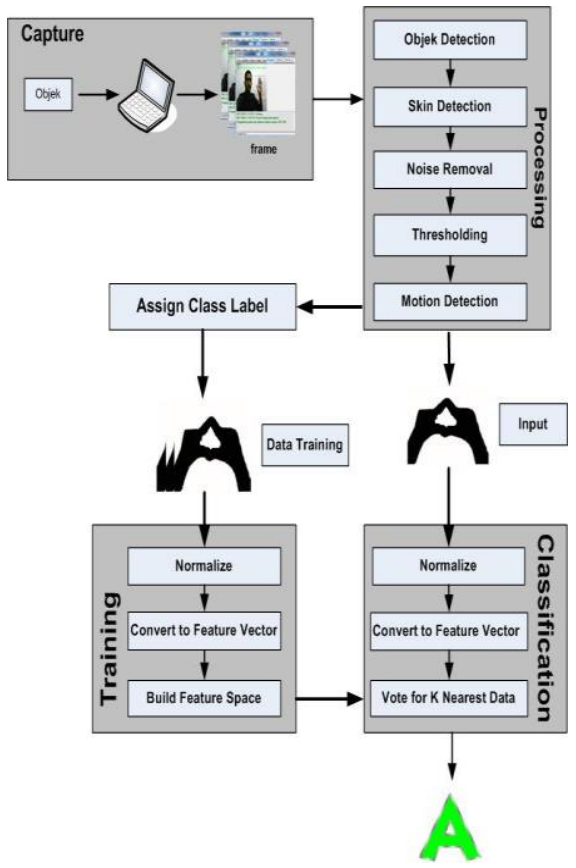

Gambar 2. Blok diagram system

Alur sistem dan mekanisme pengklasifikasian kode tangan pada bahasa isyarat dapat dilihat pada flowchart mekanisme sistem pada Gambar 3.

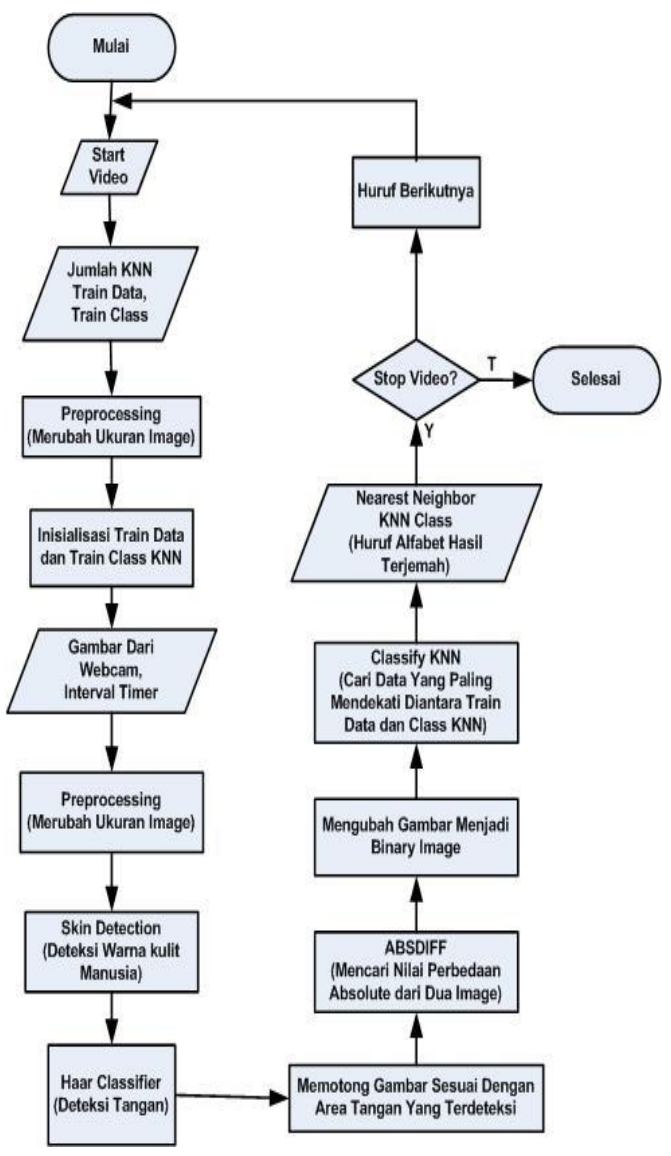




\section{HASIL DAN DISKUSI}

\section{A. Implementasi}

Untuk mendeteksi kode tangan pada bahasa isyarat langkah pertama adalah object detection. Metode yang digunakan untuk mendeteksi tangan adalah Haar Classifier. Objek tangan dideteksi dengan cara membuka tangan dan menutup tangan. Metode Haar Classifier yang membangun cascade penolakan didorong, yang bekerja dengan menolak data negatif untuk datang dengan keputusan untuk mencari data positif[7]. Hal ini belajar diawasi yang perlu pelatihan data untuk mendeteksi objek tertentu (membutuhkan pelatihan data positif dan negatif). Setelah pelatihan selesai, cascade dibangun. Didalamnya berisi tahapan yang bekerja sebagai pohon keputusan untuk menentukan objek yang akan dideteksi dan mengabaikan yang bukan objek. Proses object detection terlihat pada Gambar 4.

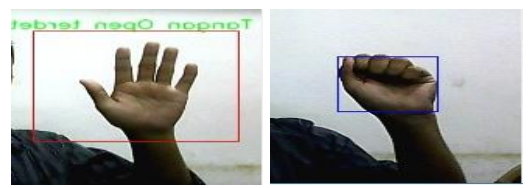

Gambar 4. Proses object detection

Setelah kode tangan bahasa isyarat dapat dikenali dengan baik maka Haar Classifier akan melakukan skin detection. Kemudian untuk memeriksa apakah data sudah terlatih maka membutuhkan proses motion detection. Sistem akan menormalkan setiap gambar biner ke 104 x 104, kemudian mengkonversi data masukan dan data klasifikasi contoh data dari matriks piksel ke vektor. Mengklasifikasikan data masukan dengan menentukan kelas mayoritas dari data ke-K terdekat. Proses motion detection dapat dilihat pada Gambar 5.

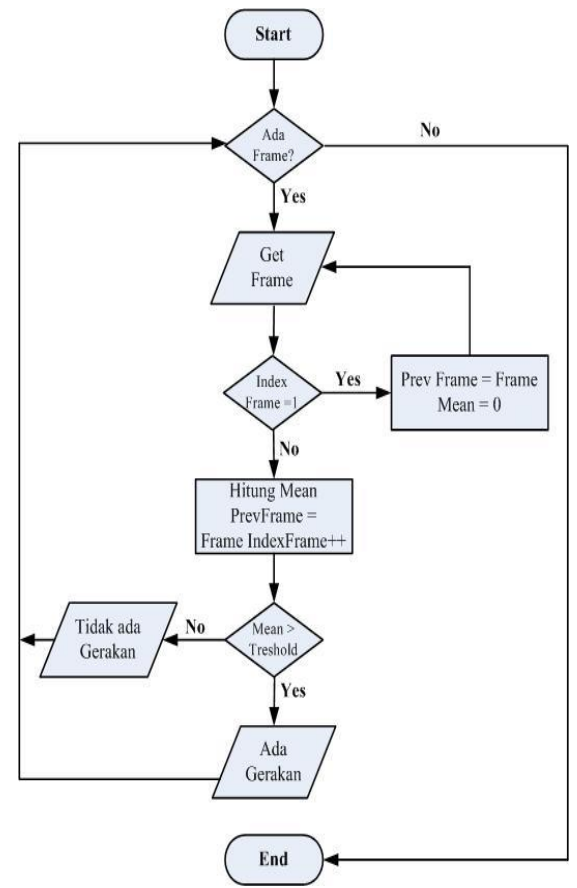

Gambar 5. Proses motion detection
Berikutnya sistem akan memeriksa data yang telah dilatih. Jika tidak memuat data sampel untuk menciptakan ruang fitur, maka sistem akan menormalkan setiap gambar biner ke $150 \mathrm{x}$ 150, mengkonversi input maupun sampel klasifikasi data data dari matriks piksel ke vektor, membangun ruang fitur, dan mengklasifikasikan input data dengan menentukan kelas mayoritas data ke-K terdekat. Pada Gambar 6 menjelaskan flowchar sistem dimana data kode tangan pada bahasa isyarat dikalsifikasikan. Algoritma K-NN menggunakan klasifikasi ketetanggaan sebagai nilai prediksi dari contoh data uji yang baru[8]. Tujuan K-NN adalah untuk mengklasifikasi objek baru berdasarkan atribut dan training sampel[9]. Ketika jumlah data mendekati tak hingga, algoritma ini menjamin error rate yang tidak lebih dari dua kali Bayes error rate (error rate minimum untuk distribusi data tertentu).

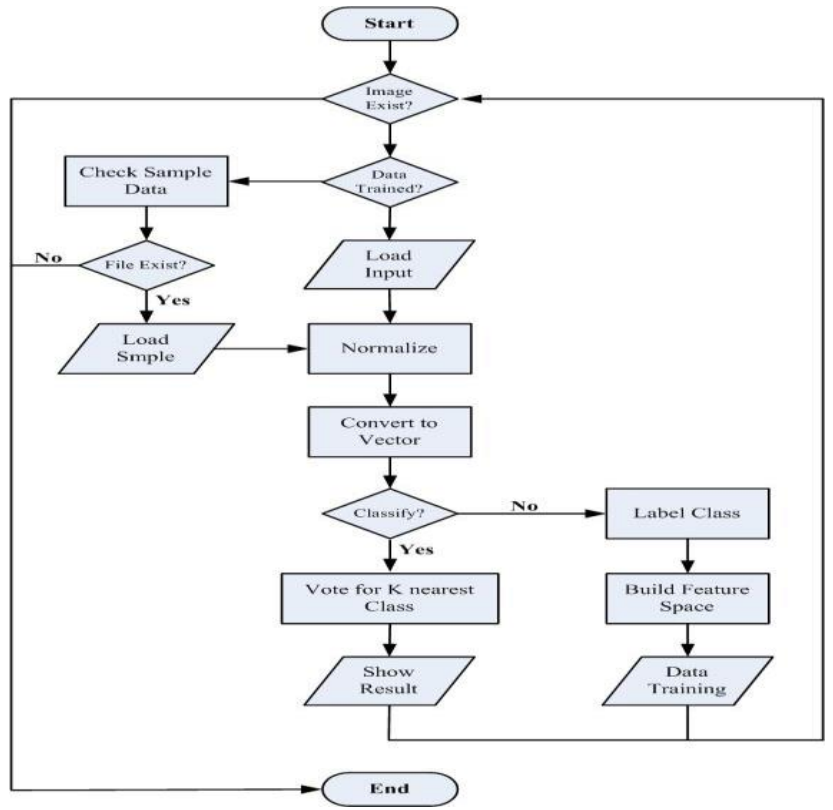

Gambar 6. Proses classifying data

\section{B. Pengujian}

Pengujian terhadap klasifikasi objek kode tangan pada pengenalan alphabet dengan Bahasa Isyarat Indonesia (BISINDO) yang telah diimplementasikan kedalam aplikasi kemudian diuji dengan pengujian terhadap jarak dan pengujian terhadap akurasi pengenalan huruf.

1) Pengujian Jarak

Pengujian ini dilakukan dengan menggunakan parameter jarak yang berbeda tetapi dengan jumlah cahaya yang sama dan posisi telapak tangan yang sama. Berikut ini adalah hasil pengujiannya pada Tabel 1 .

Dari Tabel 1 dapat dilihat bahwa jarak optimal yang mampu dideteksi oleh sistem adalah jarak $30 \mathrm{~cm}$ sampai dengan $110 \mathrm{~cm}$. Hal ini terjadi karena pada saat training data Haar Classifier, menggunakan data tangan sebesar 104x104 pixel. 
TABEL 1. DETEKSI TANGAN TERHADAP JARAK

\begin{tabular}{|c|c|c|c|c|c|}
\hline Subyek & $\mathbf{3 0} \mathbf{~ c m}$ & $\mathbf{5 0} \mathbf{~ c m}$ & $\mathbf{7 0} \mathbf{~ c m}$ & $\mathbf{9 0} \mathbf{~ c m}$ & $\mathbf{1 1 0} \mathbf{~ c m}$ \\
\hline 1 & $\mathrm{~V}$ & $\mathrm{~V}$ & $\mathrm{~V}$ & $\mathrm{~V}$ & $\mathrm{~V}$ \\
\hline 2 & $\mathrm{~V}$ & $\mathrm{~V}$ & $\mathrm{~V}$ & $\mathrm{~V}$ & $\mathrm{~V}$ \\
\hline 3 & $\mathrm{~V}$ & $\mathrm{~V}$ & $\mathrm{~V}$ & $\mathrm{~V}$ & $\mathrm{~V}$ \\
\hline 4 & $\mathrm{~V}$ & $\mathrm{~V}$ & $\mathrm{~V}$ & $\mathrm{~V}$ & $\mathrm{~V}$ \\
\hline 5 & $\mathrm{~V}$ & $\mathrm{~V}$ & $\mathrm{~V}$ & $\mathrm{~V}$ & $\mathrm{~V}$ \\
\hline 6 & $\mathrm{~V}$ & $\mathrm{~V}$ & $\mathrm{~V}$ & $\mathrm{~V}$ & $\mathrm{~V}$ \\
\hline 7 & $\mathrm{~V}$ & $\mathrm{~V}$ & $\mathrm{~V}$ & $\mathrm{~V}$ & $\mathrm{~V}$ \\
\hline 8 & $\mathrm{~V}$ & $\mathrm{~V}$ & $\mathrm{~V}$ & $\mathrm{~V}$ & $\mathrm{~V}$ \\
\hline 9 & $\mathrm{~V}$ & $\mathrm{~V}$ & $\mathrm{~V}$ & $\mathrm{~V}$ & $\mathrm{~V}$ \\
\hline 10 & $\mathrm{~V}$ & $\mathrm{~V}$ & $\mathrm{~V}$ & $\mathrm{~V}$ & $\mathrm{~V}$ \\
\hline Hasil & $\mathbf{1 0 0 \%}$ & $\mathbf{1 0 0 \%}$ & $\mathbf{1 0 0 \%}$ & $\mathbf{1 0 0 \%}$ & $\mathbf{1 0 0 \%}$ \\
\hline
\end{tabular}
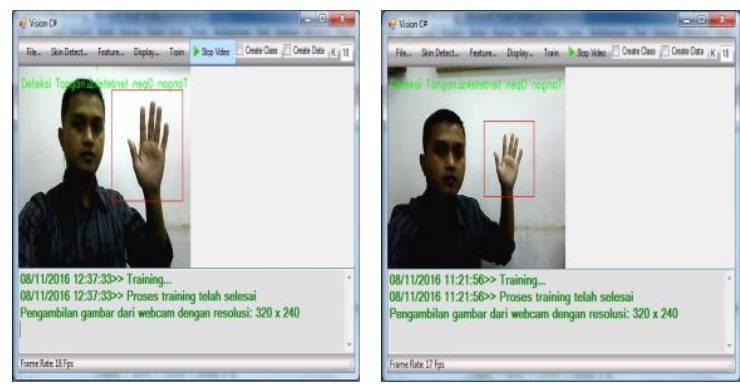

Gambar 7. Deteksi tangan dengan jarak yang berbeda

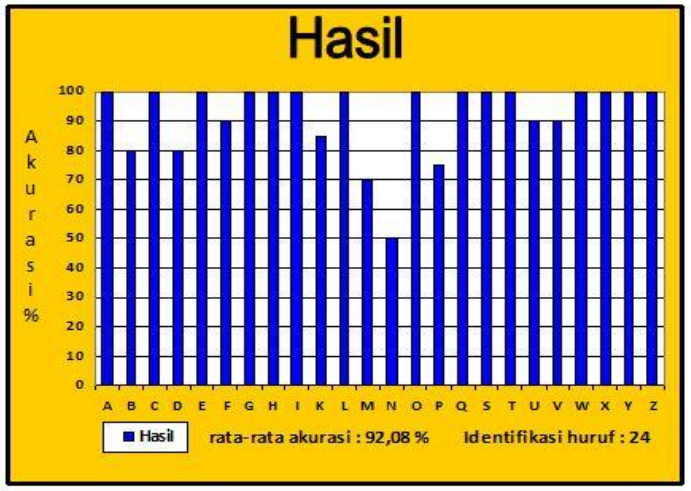

Gambar 8. Akurasi klasifikasi keseluruhan

\section{2) Pengujian Huruf}

Pada pengujian akan diklasifikasi 24 isyarat huruf yang dapat diterjemahkan yaitu huruf A, B, C, D, E, F, G, H, I, K, L, M, N, O, P, Q, S, T, U, V, W, X, Y dan Z. Pengujian ini dijalankan oleh 10 orang setiap orang memberikan 10 bentuk isyarat tangan untuk diterjemahkan. Jumlah data training yang digunakan adalah 50 data perhuruf dan nilai variabel $\mathrm{K}$ yang digunakan adalah 32. Beberapa hasil yang di bawah $90 \%$ dikarenakan bentuk tangan yang hampir mirip dengan bentuk tangan yang lainnya seperti huruf B, D, P, M, dan N. Selain itu juga ada huruf yang sulit untuk membentuknya seperti contoh huruf F, K, dan Z. Rata-rata hasil Akhir yang di dapat 91,8 \% yang terlihat seperti grafik pada Gambar 8.

\section{KESIMPULAN}

Berdasarkan penelitian yang telah dilakukan teknik yang digunakan dalam deteksi terhadap kode tangan bahasa isyarat adalah dengan menangkap posisi tangan, mengekstrak bentuk tangan tersebut, kemudian mengklasifikasinnya. Untuk mencari letak tangan dari setiap frame yang dihasilkan menggunakan Haar Classifier yang sebelumnya telah dilakukan training terlebih dahulu. Setelah bentuk tangan didapatkan, maka gambar biner bentuk tangan diklasifikasikan dengan algoritma K-Nearest Neighbors (KNN) berdasarkan kumpulan gambar-gambar isyarat tangan yang digunakan sebagai data training.

Pada hasil pengujian jarak implementasi pada aplikasi klasifikasi objek kode tangan pada bahasa isyarat mampu mendeteksi dengan jarak $30 \mathrm{~cm}$ sampai dengan $110 \mathrm{~cm}$. Sedangkan hasil pengujian klasifikasi objek dengan algoritma $\mathrm{K}$ Nearest Neigbors huruf alphabet yang dapat diterjemahkan yaitu huruf A, B, C, D, E, F, G, H, I, K, L, M, N, O, P, Q, S, $\mathrm{T}, \mathrm{U}, \mathrm{V}, \mathrm{W}, \mathrm{X}, \mathrm{Y}$, dan $\mathrm{Z}$. Huruf $\mathrm{J}$ dan $\mathrm{R}$ tidak dapat diterjemahkan karena berbentuk gerakan tangan. Rata-rata hasil Akhir yang di dapat 91,8 \%. Namun ada beberapa hasil yang di bawah $90 \%$ dikarenakan bentuk tangan yang hampir mirip dengan bentuk tangan yang lainnya seperti huruf $B, D$, P, M, dan N. Selain itu juga ada huruf yang sulit untuk membentuknya seperti contoh huruf F, K, dan Z.

\section{UCAPAN TERIMAKASIH}

Terimakasih SLB Dharma Bhakti Dharma Pertiwi Bandar Lampung dan DPP GERKATIN (Gerakan untuk Kesejahteraan Tunarungu Indonesia) DKI Jakarta.

\section{DAFTAR PUSTAKA}

[1] DPD GERKATIN DKI JAKARTA, "Berkenalan Dengan Bahasa Isyarat Indonesia (BISINDO)”, DPD GERKATIN DKI JAKARTA, 2010.

[2] Sutoyo dkk, "Teori Pengolahan Citra Digital", Yogyakarta: Andi, 2009.

[3] G. Goujon, Chaoqun, W. Jianhong, "Data Clustering :Theory, Algorithms, and Applications", Virginia: ASA, 2007.

[4] E. Budianita, Jasril, L. Handayani,"Implementasi Pengolahan Citra dan Klasifikasi K-Nearest Neighbour Untuk Membangun Aplikasi Pembeda Daging Sapi dan Babi”, Jurnal Sains, Teknologi dan Industri, Vol. 12, No. 2, Juni 2015, pp.242 - 247.

[5] F. Liantoni, "Klasifikasi Daun Dengan Perbaikan Fitur Citra Menggunakan Metode K-Nearest Neighbor", ULTIMATICS, Vol. VII, No. 2, Desember 2015.

[6] N. Syafitri, "Perbandingan Metode K-Nearest Neighbor (KNN) dan Metode Nearest Cluster Classifier (NCC) Dalam Pengklasifikasian Kualitas Batik Tulis", Jurnal Teknologi Informasi \& Pendidikan, Vol. 2 No. 1, September 2010.

[7] J. P. Rakhman, N. Ramadijanti, and E. Satriyanto, "Translasi Bahasa Isyarat,"Jurnal PENS ITS, Surabaya, 2012.

[8] X. Wu, V. Kumar, "The Top Ten Algorithms in Data Mining", New York: CRC Press, 2009.

[9] D. Larose, "Discovering Knowledge in Data", USA: John Wiley's and Son, 2005 